\title{
Public Sector Supply Chain Management: A Triple Helix Approach to Aligning Innovative Environmental Initiatives
}

\author{
Azley Abd Razak \\ Lecturer, University of the West of England. Address: Coldharbour Ln, Bristol BS16 1QY, UK. \\ E-mail: Azley.Abdrazak@uwe.ac.uk \\ Martyn Rowling \\ Lecturer, University of South Wales. Address: Treforest Pontypridd CF37 1DL, UK. \\ E-mail: martyn.rowling@southwales.ac.uk \\ Gareth White \\ Senior Lecturer, University of South Wales. E-mail: gareth.white@southwales.ac.uk \\ Rachel Mason-Jones \\ Senior Lecturer, University of South Wales. E-mail: rachel.mason-jones@southwales.ac.uk
}

\begin{abstract}
This paper argues that in order to deliver greater levels of sustainable performance, environmental strategy should be addressed at the supply chain level and not just at the level of the individual organisation. It demonstrates the similarities between the environmental statements of companies in both the private and public sectors and proposes that public sector organisations, by virtue of their considerable spend with private sector organisations, are in a powerful position to encourage and support environmental initiatives throughout their supply chains. Drawing upon Triple Helix Theory the paper discusses the

importance of unifying the efforts of government, industry and academia in order to identify and operationalise innovative thinking in economies. It explores the roles of public and private sector organisations along with universities in developing environmental strategies and practices within supply chains. Environmental Management Systems (EMS) are discussed and the EcoManagement and Audit Scheme (EMAS) is identified as a potential mechanism for structuring and reporting the collaborative environmental improvement performance of supply chains.
\end{abstract}

Keywords: green supply chain management; performance; university; industry; engagement; alignment

DOI: $10.17323 / 1995-459 x .2016 .1 .43 .52$
Citation: Abd Razak A., Rowling M., White G., Mason-Jones R. (2016) Public Sector Supply Chain Management: A Triple Helix Approach to Aligning Innovative Environmental Initiatives. Foresight and STI Governance, vol. 10, no 1, pp. 43-52. DOI: 10.17323/1995459x.2016.1.43.52 
$\mathrm{T}$ he relationship between the holistic performance of supply chains and the satisfaction of end consumers is strong. Diverse globalized markets require tailored yet flexible supply strategies [Butner, 2010; Piercy et al., 2010; Hameri, Hintsa, 2009; Jain, Benyoucef, 2008; Blowfield, 2005; Childerhouse, Towill, 2000; Shi et al., 1997]. However, spatially distributed supply lines also introduce increased political, economic, and natural risks to already complex operations [Wilding, 2012; Manuj, Mentzer, 2008]. The risks and difficulties associated with ever-expanding globalized supply chains have subsequently led to a significant rise in strategies to repatriate sources of supply where possible [Brosze, 2010; Hameri, Hintsa, 2009; Christopher et al., 2006].

The importance of managing 'green' issues in organizations has been recognized for a considerable length of time [Plant et al., 2015; White et al., 2014a; White, James, 2014; Chan et al., 2013; Pane Haden et al., 2009] and corporate attitudes towards the environment have become of increasing concern to the public [DEFRA, 2011; Clark, 2004]. Environmental issues are pertinent to both public and private sector organizations and they are increasingly becoming key elements of many organizations' strategies; further, there is an expectation to evidence the environmental performance of the supply chain. Given the continuing pressures to improve profitability and manage risks, Supply Chain Managers walk a thin line between balancing cost reduction and maintaining the provision of service and supply [Manuj, Mentzer, 2008; Hong-Minh et al., 2000].

This paper proposes that by aligning the efforts of government, university, and private sector organizations in supply chains through the framework of EMAS, greater potential holistic environmental performance can be achieved. This improved performance, when aligned correctly with stakeholder requirements, will also be of added economic and social benefit to those organizations comprising the supply chain. The approach can also be of assistance to small and medium sized organizations that account for the majority of national economic activity [URS, 2010] and typically experience great difficulty in developing and implementing quality and environmental management systems [White et al., 2009; 2014a]. It may also be a valuable initiative that will minimize the potentially deleterious effect of increased levels of manufacturing, should the trend to repatriate sources of supply continue.

\section{Public and Private Sector Strategic Procurement}

Procurement can be divided broadly into that which is undertaken in the private sector and that which is undertaken in the public sector. Collectively they comprise a considerable proportion of national economic activity [Hoctor, Keating, 2009]. Both public and private sector procurement face similar problems with respect to balancing cost reductions against quality of supply and service, although the public sector tends to be more highly regulated, and therefore constrained [Linnaet al., 2010; Schapper et al., 2006].

The public sector traditionally has viewed procurement as a clerical activity and has based purchasing decisions on the issue of cost [Quayle, Quayle, 2000]. The importance of the procurement function is now recognized, and increasingly plays a strategic role within public sector organizations. This change has been driven by increasingly complex product choices, heightened use of technology, a switch in focus from cost to best value, and in line with this paper's perspective, an increased consideration of environmental issues [Zheng et al., 2007; Beukers et al., 2006; Paulraj et al., 2006; Gelderman, van Weele, 2005; McCue, Gianakis, 2001; Cavinato, 1999; Reck, Long, 1988; Caddick, Dale, 1987]. Many authors agree that procurement has become increasingly recognized at the corporate level with some suggesting that it should be considered equally important like other strategically significant functions such as marketing, finance, and operations [Paulraj et al., 2006; Cavinato, 1999; Rink, Fox, 1999; McIvor et al., 1997]. Despite this, it has been observed that public sector procurement is still focused on reducing transaction costs and fails to consider the total acquisition costs of products [Staples, Dalrymple, 2011].

Developing an effective and strategic procurement function is becoming increasingly a priority for managers who recognize that it has a definitive role in the ultimate success of the public sector [Deasy et al., 2014; Matthews, 2005]. Despite the increasing recognition of the need to develop a strategic approach to public sector procurement, the academic focus has largely been based on the private sector [Murray, 2001] and on conceptual frameworks [Cousins et al., 2006], although it is recognized that some researchers have attempted to address this [Quayle, 1998; Quayle, Quayle, 2000; Beukers et al.,2006].

Some argue that strategic procurement can incur costs for organizations, particularly with the introduction of e-business [Angeles, Nath, 2007]. This includes costs including purchase of technology and associated training, and learning curve and maintenance costs, which potentially increase business risk. However, it can also be shown that the long-term benefits of developing strategic procurement practices far outweigh the up-front costs, with many agreeing that such an approach actually improves the financial performance of an organization [Vickery et al., 2003; Carr, Smeltzer, 1999; Carter, Narasimhan, 1996]. Biemans and Brand claimed 'that the strategic management of procurement may trim procurement expenditure between 5-15 per cent over a three-year period' [Biemans, Brand, 1995, p. 400]. At the same time, recent austerity measures have further stressed the importance of controlling public expenditure, 
exemplified by a KMPG survey of senior executives in the public sector that indicated $67 \%$ were 'planning to reduce procurement costs' [KPMG, 2010].

Although there are many differences between the public and private sectors, and the literature often treats them as separate entities, they are in fact mutually dependent. The public sector spends on all manner of inputs, while services are outsourced to private sector organizations. Consequently, the public sector is a source of potential business for the private sector; correspondingly, private sector companies are potentially sources of innovation and increased value for money for the public sector.

Public sector organizations are therefore in a position to direct and influence the strategic goals of their suppliers, through introducing mandatory contractual requirements, or suggesting and supporting complementary initiatives. The next section discusses the importance of addressing environmental issues at the level of the supply chain and not just at the level of the individual organization. This affords the opportunity of utilizing public sector procurement strategy to influence the increasing importance of the environmental performance of entire supply chains.

\section{Environmental Dimension of Strategic Procurement}

The internal motivation to improve environmental performance is primarily driven by its potential economic benefits [Markley, Davies, 2007], but organizations are also facing increasing external pressure to reduce their environmental impact. These pressures arise from legislation that governs the effects of their actions and often imposes targets for emissions and waste reduction [White et al., 2014a; 2014b; Chan et al., 2013]. External pressure also arises from the market's complex expectations that an organization will endeavour to act responsibly for the long-term benefit of the wider society [DEFRA, 2011]. This expectation for responsible behaviour is increasingly being extended to the supply chain, with supply chains of companies being expected to perform within required boundaries. Consequently, the strategic directions of organizations are not based upon financial measures alone [Finkbeiner et al., 1998].

Therefore, environmental strategy can be seen as a common focus among a wide variety of organizations. Indeed, it may be argued that the aim of any organization's environmental strategy is to reduce and then minimize its deleterious effect upon the environment, even if the means by which they translate the requirements into action vary widely. Table 1 presents excerpts of the environmental policies and statements of a sample of public and private sector organizations, taken from documents freely available via their websites, and shows their similar intentions toward environmental management and improvement. Organizations in different fields recognize their responsibility towards the wider environment. Some also state their responsibility toward improving society and others make reference to specific measures of performance such as the reduction of fossil fuel and carbon dioxide emissions. Cardiff Council in Wales, in agreement with the assertions made in this paper, highlights the importance of collaborative working and partnering to improve environmental performance.

Therefore, it is reasonable to deduce that the environmental strategies of organizations within supply chains and networks share similar overall aims, which are fundamentally to manage and improve their impact upon the environment. In practice however, there is evidence to show that some organizations are compelled to act individualistically and pursue the attainment of their own immediate operational and environmental goals rather than focus on the holistic performance of the supply chain. This prevents other organizations in the supply chain from making improvements in their own environmental performance [White et al., 2014b]. This self-interested approach, while beneficial to the individual organization and its environmental performance, may affect the holistic environmental improvement potential of supply chain leading to a reduced competitive advantage. Treating 'green' issues at the level of the supply chain rather than the individual organization may, therefore, be an approach that yields greater overall environmental impact and benefit.

Reiterating the point made in the previous sections, public sector organizations are in a position to direct and influence their suppliers; therefore, to some degree, the environmental activities of entire supply chains. However, adopting this approach implies that the strategic role of the public sector procurement function may become even more significant. This is somewhat problematic since the function already faces considerable pressures in meeting current requirements and challenges. Rather than burdening an already highly pressured discipline, the next section draws on Triple Helix theory to recognize the complementary roles of government, industry, and universities in delivering innovation and how they may be aligned to address the increasingly important aspect of supply chain environmental performance improvement.

\section{Triple Helix}

The evolutionary Triple Helix model was developed by Etzkowitz \& Leydesdorff [Etzkowitz, Leydesdorff,1995]. It describes the different degrees of collaboration between the three main actors 
involved in national innovation, namely government, universities, and industry. The term Triple Helix is an analogy for the central idea that when each helix (actor) is linked to each other, the overall value of collaboration is strengthened [Etzkowitz, 2003, 2008]. The model depicts three different degrees of collaboration, termed statist, laissez faire and hybrid, which relate to different outcomes in terms of maximizing national innovation potential. It suggests that for a country to grow through its innovation strategy, it must make the transition from statist and laissez-faire positions towards a hybrid triple helix position.

The defining characteristic of the statist position is that the government controls academia and industry. A major element of this is that the government plays the major role in 'driving' academia and industry, while at the same time planning the control to organize them to encourage innovation. Meanwhile, industry is regarded as the national champion, while the university's role is mainly reduced to teaching and academic research [Etzkowitz, 2003; Ranga, Etzkowitz, 2010]. However, with this model, government or industry will not be able to exploit the potential knowledge generation activities within universities as both teaching and research tend to be far removed from industry needs and universities do not have any incentive to engage in the commercialization of research [AbdRazak, White, 2015; Etzkowitz, 2003).

In the laissez-faire model, governments, universities, and industry operate independently as separate institutional spheres [Etzkowitz, 2003]. It is expected that firms in an industry should operate separately in competitive relationships and should only be linked through the market. The government would be limited to addressing only those problems that can be defined as market failures. In the laissez-faire condition, industry is the driving force, with the other two spirals acting as ancillary supporting structures [Ibid.]. In this model, the individualistic mentality is more prominent and creates a type of heroic entrepreneur. The advantage of this model is that industry can grow without any undue interventions by government [AbdRazak, Saad, 2007]. The downside to this is that the system makes it difficult for

\section{Table. 1. Sample of Environmental Strategy Statements}

\begin{tabular}{|c|c|}
\hline Organization & Statement \\
\hline Cardiff Council & $\begin{array}{l}\text { Cardiff Council acknowledges its role and responsibility for the protection and enhancement of the } \\
\text { environment. Through sustainable development, as laid out in the Sustainable Development Policy } \\
\text { Statement and Action Programme, the Council recognizes that action at a local level will bring global } \\
\text { benefits through preserving the environment and its resources for future generations. } \\
\text { Cardiff Council believes that it has a role to lead by example and help deliver environmental } \\
\text { improvements both within the organization, as well as through partnership and collaborative working. }\end{array}$ \\
\hline Tata Steel & $\begin{array}{l}\text { We are an integral part of our local communities and try to improve the quality of life in them by } \\
\text { supporting them not only in their local economies but also in social development, education, health, } \\
\text { safety and the environment. } \\
\text { To reduce the resources that we consume, we are continually improving the efficiency of the processes } \\
\text { we use to make strip steel. We are committed to making strip steel better and thereby reducing its impact } \\
\text { on the environment. }\end{array}$ \\
\hline NHS Wales & $\begin{array}{l}\text { In delivering our role as a healthcare provider, we acknowledge our responsibility to protect our local } \\
\text { environment and assist with practices that will deliver national and international targets. } \\
\text { We have acknowledged this responsibility by undertaking an environmental review of our activities and } \\
\text { compiling an aspects register of all the environmental impacts that this Trust has. }\end{array}$ \\
\hline Redrow PLC & $\begin{array}{l}\text { We at Redrow understand that we have a part to play in ensuring that our business and our products } \\
\text { have minimum impact on the environment and climate and that we must work towards reducing } \\
\text { reliance on fossil fuels, cutting down energy demands and carbon emissions. }\end{array}$ \\
\hline Welsh Water & $\begin{array}{l}\text { Understanding how Welsh Water impacts on the wider environment and the actions we can take to } \\
\text { minimize any adverse effects is a key objective for the business. } \\
\text { We are committed to identifying and accounting for the environmental implications of all of our } \\
\text { activities, and for recognizing and considering opportunities for economically sustainable environmental } \\
\text { benefit. }\end{array}$ \\
\hline Brains Brewery & $\begin{array}{l}\text { The commitment is to measure and reduce the carbon footprint of business activity in four areas: } \\
\text { Company - Employees - Customers - Suppliers }\end{array}$ \\
\hline The Celtic Manor & $\begin{array}{l}\text { The Celtic Manor Resort recognizes its moral and social responsibilities to the environment and it is } \\
\text { committed to developing an environmentally responsible business. } \\
\text { We appreciate that environmental management is an issue of on-going concern for our customers, staff, } \\
\text { and suppliers and know that it requires constant reassessment, monitoring, and continual improvement. }\end{array}$ \\
\hline BBC & $\begin{array}{l}\text { Environmental management is integral to [the environmental] vision and our performance. Our overall } \\
\text { objective is to carry out our operations in a way, which manages, minimizes, and continually reduces our } \\
\text { adverse environmental impacts and demonstrates pollution prevention. }\end{array}$ \\
\hline
\end{tabular}


the three institutional spheres to interact to maximize the synergy in the relationships [Etzkowitz, 2008]. Industries can be very strong in their own area but lacking in understanding and ability to capture the dynamic needs of their external environment that includes customers, suppliers, and other institutions [Etzkowitz, 2002; AbdRazak, Saad,2007; Ranga, Etzkowitz, 2010].

Both the statist and laissez-faire positions are seen to compromise the innovation potential of a nation since they do not lead to the degree and type of collaboration that capitalizes on the synergies between actors as described in the hybrid Triple Helix position. According to Etzkowitz, if countries evolve from these states it will help all three actors and the nation to achieve their long-term strategic goals [Etzkowitz, 2003].

One of the key aspects of the hybrid Triple Helix model is the emphasis on the importance of academia in the capitalization of knowledge. Etzkowitz believes that universities need to be the main drivers of its development [Etzkowitz, 2003]. Universities are expected to take on a generating role in directing regional economic development through 'academic entrepreneurial' activities that share common characteristics with the traditional roles of industry and the government in economic regulation [Etzkowitz, Leydesdorff, 1997, 1999]. The development of the 'entrepreneurial university' is a unique feature of the evolutionary Triple Helix model of innovation. Etzkowitz et al. [Etzkowitz et al., 2000, p. 326] define this new type of university as the 'amalgam of teaching and research, applied and basic, entrepreneurial and scholastic interests. The development of entrepreneurial universities is seen as key to the dynamic processes of evolution required to enhance innovation. Etzkowitz and Klofsten describe the hybrid Triple Helix position as characterized by the following elements [Etzkowitz, Klofsten, 2005]:

1. A prominent role for the university in innovation, on a par with industry and government in a knowledge-based society.

2. A movement towards collaborative relationships among the three major institutional spheres in which innovation policy is an outcome of their interactions rather than a prescription from the government. According to Inzelt, one of the roles of government within the Triple Helix is to encourage industry by minimizing the risk of partnership building with a strong scientific base [Inzelt, 2004].

3. In addition to fulfilling their traditional functions, each institutional sphere also 'takes the role of the other' [Etzkowitz, Klofsten, 2005].

\section{Benefits and Challenges of Hybrid Triple Helix Cooperation}

Martin [Martin, 2000] and Schartninger et al. [Schartninger et al., 2001] have all emphasized that businesses in the private sector can increase their innovation capacity and improve their competitive positions through collaboration with universities. This provides access to basic and applied research, economically relevant scientific and technological knowledge, prototypes that can be developed and tested, and enables the businesses to get support in finding solutions for their products' problems. Meanwhile, universities gain benefits from cooperating with industry by adding financial resources, new technical knowledge and good practices, and access to industrial information and applied knowledge for academic research and teaching [Martin, 2000].

Nieminen and Kaukonen [Nieminen, Kaukonen, 2001] describe how the involvement in joint technological development projects with other organizations and scientific and technological institutions, namely universities, is a promising approach for firms looking for real competitive advantages through technological differentiation. These findings exemplify the view of Etzkowitz and Leydesdorff [Etzkowitz, Leydesdorff, 1997] that the university-industry relationship emerges as a sophisticated instrument for the reinforcement of firms' competitive position through adopting advanced, innovative, and value-added technologies.

A wide range of barriers has been recognized in the literature including not appreciating other perspectives or not understanding other sectors' demands and contexts [de Castro et al., 2000]. This is problematic since Etzkowitz [Etzkowitz, 2003] state that for a hybrid Triple Helix status to be achieved each institution should keep its own distinctive characteristics, while at the same time assuming the role of the other and gaining value from each other.

Differences in university and industry agendas in terms of research generation, for instance, may hinder the relationship. Industry, on the one hand, seeks commercialization whereas universities often seek knowledge-driven innovation. Therefore, collaboration with industry is likely to increase pressure for short-term research, thereby negatively affecting long-term basic and curiosity-driven research [Lee, 1997]. Industry-orientated drive for research or, as Feller [Feller, 1990] notes, the privatization of research, may actually slow down the rate of technological and knowledge-driven, university-led, research and innovation needs.

The differing perspectives on intellectual property represent another source of conflict, with entrepreneurs finding it difficult to figure out the academic ontological principles related to the universality of 
knowledge that do not coexist well with private property values [Nieminen, Kaukonen, 2001]. A clash between organizational cultures is also another potential barrier [Wolff, 1994], with partners having to set up project management and 'skunk' teams to unify cultural differences. Differences in culture may generate their own set of associated problems and sources of conflict such as communication problems. For instance, the academic language tends to be eclectic and speculative, while the entrepreneurial one tends to be more focused and practical [Nieminen, Kaukonen, 2001].

\section{Proposition}

The hybrid Triple Helix model offers a useful conceptualization of how government, university, and industry can be organized to deliver innovation in economies. It can be argued that the cascading of transnational environmental objectives into organizational goals should be capable of aligning the actions of the three groups of actors, but evidence shows that this is not always the case [White et al., 2015]. Triple Helix theory and practice state that the collaborative efforts of actors are capable of delivering greater overall benefits than if each were to pursue their own goals individually. This arrangement is simple to envisage, although its practical execution is more complicated. The primary challenge lies in aligning the needs and expectations of each of the actors and developing the necessary collaborative relationships. The use of the public sector as a driver for this by enabling a coordinated approach to supply chain management and research funding development would enable the Triple Helix to flourish effectively.

The pursuit of environmental improvement may be a common factor that can be used to align the efforts and initiatives of Triple Helix actors. Government is concerned with meeting transnational agendas such as those that derive from the Bruntland Report [UN, 1987]. Organizations (i.e. firms) are challenged with meeting the requirements of national environmental standards and regulations as well as satisfying the expectations of an increasingly environmentally aware customer and stakeholder base. Universities are interested in both acquiring knowledge of the current environmental, organizational and sociological conditions, and in developing new knowledge and technologies that can improve those conditions.

\section{Environmental Management Systems}

The environmental management systems (EMS) ISO 14001 and the Eco-Management and Audit Scheme (EMAS) are the most common approaches organizations take toward improving their environmental performance [EMAS, 2006; Ruzicka, 2004; Chemical Week, 1997]. Initially seen and promoted as different approaches, they are now complementary with EMAS and conceived as a development of, and logical progression from, the attainment of ISO 14001 certification [Palomares-Soler, Thimme, 1996; Klaver, Jonker, 1998; IEMA, 2009; Chemical Week, 1998; Roberts, 1995a; 1995b; 1996].

The benefits of an effective EMS can be greater than simply an improvement in environmental performance. There may be internal operational and cost benefits as well as positive effects upon environmentally aware employees. Furthermore, the external benefits may also include the acquisition of additional business resulting from improved perceptions of company image [ White, Lomax, 2010; Hillary, 2004; IEMA, 2009; Strachan et al., 1997).

The challenges of implementing EMAS are however significant and are not simply related to cost and resource issues [White et al., 2014a]: knowledge of relevant legislation, the need to publicly disclose operational information, and difficulty in establishing relevant and realistic measures of performance all present further difficulties [IEMA, 2011; Hillary, 2004; Honkasalo, 1998; Klaver, Jonker, 1998]. In the United Kingdom, the BS8555 'Acorn' scheme [IEMA, 2009] provides a common pathway for SMEs to work towards EMAS and ISO 14001 certification. The attainment of ISO 14001 certification provides assurance that the environmental management systems are robust, while EMAS certification requires the public disclosure of environmental initiatives and mishaps.

\section{EMAS and the Roles of Triple Helix Actors}

Through stipulating the pursuit of EMAS throughout their supply chains, public sector organizations are capable of driving efforts toward realizing the national environmental strategy. This, in turn, aids in the attainment of transnational environmental objectives and agreements. EMAS thus becomes the 'mutually shared value' that stimulates actors' efforts within the Triple Helix model.

Consequently, organizations within public sector supply chains are tasked with publicly disclosing their environmental initiatives. They also focus more on improving their environmental impact rather than becoming preoccupied with the robustness of their internal environmental management systems. This measurable 'real world' improvement, and the public disclosure of efforts, means that stakeholders of 
the relevant organizations concerned can greater appreciate the latter's commitment toward improving environmental performance. Ultimately, this results in improved operational performance and business opportunity (Figure 1).

While EMAS requires organizations to report their individual environmental initiatives, the collective reporting of entire supply chains' efforts may be capable of delivering greater overall benefit. Evidence of collaborative initiatives may well provide environmentally conscious stakeholders with a greater appreciation of the efforts that organizations are making. In turn, this can stimulate further business opportunities that EMAS is known to deliver for single companies.

Public sector organizations, supported by a university, are in a position to monitor the environmental performance of supply chains, as shown by the example in [Harris et al., 2011; Hervani et al., 2005]. This brings an opportunity to align improvement initiatives to attain the greatest overall benefit. This may be a significant development in approaches to environmental management as it overcomes the individualistic and self-interested perspective seen in some instances.

Achieving EMAS certification is, however, not a straightforward undertaking, particularly for smaller organizations. By aligning the efforts of entire supply chains toward achieving EMAS however, there are increased opportunities for mutual collaboration and assistance. Universities, for instance, are well placed to nurture developmental and collaborative initiatives by identifying and securing appropriate funding, and facilitating change programmes. For example, in the United Kingdom government funded mechanisms such as Knowledge Transfer Accounts (KTA), Knowledge Transfer Partnerships (KTP), Knowledge Exchange Opportunities (KEP) and Strategic Insight Programmes (SIP) exist that aim to stimulate collaboration between universities and industry. ${ }^{1} \mathrm{KTPs}$, in particular, have been highly successful in delivering a wide range of projects of great value to organizations and their partnering academic institutions, including the achievement of ISO 14001 and EMAS certification [White et al.,2009, 2014a]. These mechanisms reduce the cost and risk of undertaking complex projects for small and large businesses, providing access to the knowledge and expertise that universities possess.

In this paper, we have discussed how the environmental strategies of organizations are outwardly similar, but the means by which they are achieved are often very different. This is largely due to the varying nature of businesses that involves different materials, processes, and products. Through coordinated

Fig. 1. Triple Helix approach to aligning innovative environmental initiatives in the supply chain using EMAS

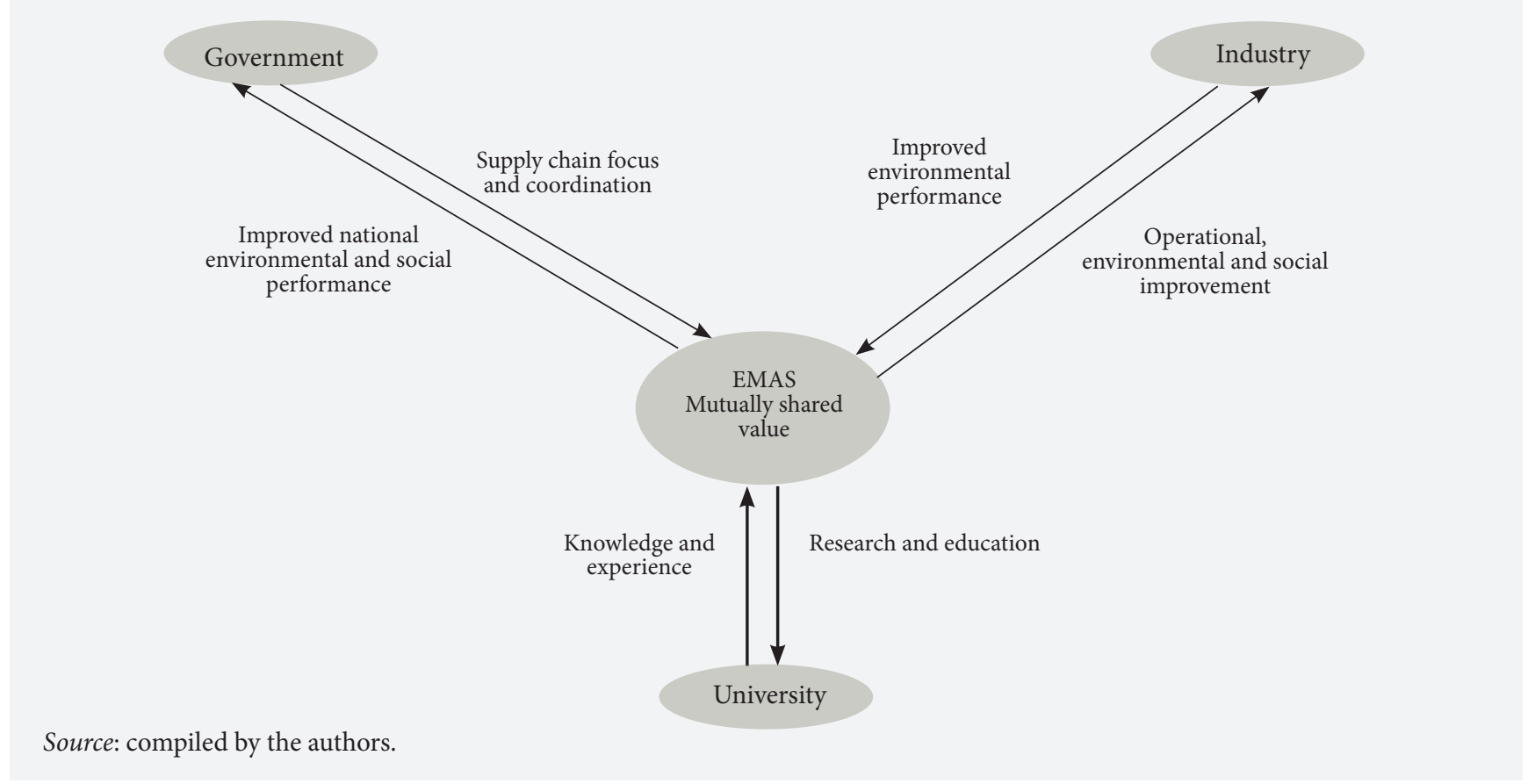

${ }^{1}$ For more information on these mechanisms, see websites of the UK Engineering and Physical Sciences Research Council (http://www.esrc.ac.uk/, accesed 01.02.2016) and Strategic Insight Programmes (http://www.siprogramme.org.uk/, accessed 01.02.2016). 
collaboration throughout the supply chain, supported by university knowledge and expertise, the available resources can be focused on discovering and developing technologies for the greatest overall environmental improvements of the supply chain. Furthermore, as universities are likely to be involved in the monitoring and development of multiple public sector organization supply chains, there are greater opportunities for identifying and sharing knowledge and technologies across businesses and sectors. This improvement in technological competitive advantage is a key outcome of successful hybrid Triple Helix operation and leads to national economic improvement.

\section{References}

Angeles R., Nath R. (2007) Business-to-business e-procurement: Success factors and challenges to implementation. Supply Chain Management: An International Journal, vol. 12, no 2, pp. 104-115.

Beukers M., Versendaal J., Batenburg R., Brinkkemper S. (2006) The procurement alignment framework construction and application. Wirtschaftsinformatik, vol. 48, no 5, pp. 323-330.

Biemans W.M., Brand M.J. (1995) Reverse marketing: A synergy of purchasing and relationship marketing. International Journal of Purchasing \& Materials Management, vol. 31, no 3, pp. 29-37.

Blowfield M.E. (2005) Going global: How to identify and manage societal expectations in supply chains (and the consequences of failure). Corporate Governance, vol. 5, no 3, pp. 119-128.

Brosze T. (2010) Future Global Supply Chain Logistics: Coming Back Closer to Home as a Consequence of Rising Energy Cost? Paper presented at the EARTO Annual Conference, Gothenburg, 20 ${ }^{\text {th }}$ May 2010, Fir Rwth Aachen. Available at: http://www.earto.eu/fileadmin/content/01_Seminars__Conferences/AC_2010/2-Tobias-Brosze.pdf, accessed 04.12 .2012

Butner K. (2010) The smarter supply chain of the future. Strategy and Leadership, vol. 38, no 1, pp. 22-31.

Caddick J., Dale B. (1987) The Determination of Purchasing Objectives and Strategies: Some Key Influences. International Journal of Physical Distribution \& Materials Management, vol. 17, no 3, pp. 5-16.

Carr A., Smeltzer L. (1999) The Relationship of strategic purchasing to supply chain management. European Journal of Purchasing \& Supply Chain Management, vol. 5, no 1, pp. 43-51.

Carter J.R., Narasimhan R. (1996) Is purchasing really strategic? International Journal of Supply Chain Management, vol. 32, no 1, pp. 20-28.

Cavinato J. (1999) A general methodology for determining a fit between supply chain logistics and five stages of strategic management. International Journal of Physical Distribution \& Logistics Management, vol. 29, no 3, pp. $162-180$.

Chan H.K., Wang X., White G.R.T., Yip N. (2013) An Extended Fuzzy-AHP Approach for the Evaluation of Green Product Designs. IEE Transactions on Engineering Management, vol. 60, no 2, pp. 327-339.

Chemical Week (1997) Leads on EMAS Sites. Chemical Week, vol. 159, no 37, p. 8.

Chemical Week (1998) EU Prepares EMAS Overhaul. Chemical Week, vol. 160, no 23, p. 6.

Childerhouse P., Towill D. (2000) Engineering supply chains to match customer requirements. Logistics Information Management, vol. 13, no 6, pp. 337-346.

Christopher M., Peck H., Towill D. (2006) A taxonomy for selecting global supply chain strategies. The International Journal of Logistics Management, vol. 17, no 2, pp. 277-287.

Clark D. (2004) The Rough Guide to Ethical Shopping, London: Penguin.

Cousins P., Lawson B., Squire B. (2006) An empirical taxonomy of purchasing functions. International Journal of Operations \& Production Management, vol. 26, no 7, pp. 775-794.

de Castro E.A., Rodrigues C., Esteves C., da Rosa Pires A. (2000) The triple helix model as a motor for the creative use of telematics. Research Policy, vol. 29, pp. 193-203.

Deasy M., White G.R.T., Parfitt S., Ringwald K. (2014) Asymmetric Procurement in the Public Sector. Strategic Change, vol. 23, no 1-2, pp. 21-29.

DEFRA (2011) Attitudes and Knowledge Relating to Biodiversity and the Natural Environment 2007-2011, London: Department for Environment, Food \& Rural Affairs.

EMAS (2006) EMAS in figures (EMAS Newsletter 2006). Available at: http://www.iema.net/stream.php/download/ readingroom/article/EMAS\%20Newsletters/EMAS\%20Newsletter\%202006\%20issue\%204\%20EMAS\%20in\%20 Education.pdf, accessed 07.07.2009.

Etzkowitz H. (2002) Incubation of Incubators: Innovation as a Triple Helix of University-Industry-Government Networks. Science \& Public Policy, vol.29, no 2, pp. 115-128.

Etzkowitz H. (2003) Innovation in innovation: The Triple Helix of university-industry-government relation. Social Science Information, vol. 42, no 3, pp. 293-338.

Etzkowitz H. (2008) Triple Helix Innovation: Industry, University and Government in Action. London; New York: Routledge.

Etzkowitz H., Klofsten M. (2005) The innovating region: Toward a theory of knowledge-based regional development. R\&D Management, vol.35, no 3, pp. 243-255.

Etzkowitz H., Leydesdorff L. (1995) The Triple Helix: University-industry-government relations. A laboratory for knowledge based economic development. EASST Review. European Society for the Study of Science \& Technology, vol. 14, no 1 , pp. 18-36.

Etzkowitz H., Leydesdorff L. (1997) Universities in the Global Knowledge Economy: The Triple Helix of UniversityIndustry-Government Relations, London: Cassell Academic. 
Etzkowitz H., Leydesdorff L. (1999) The future location of research and technology transfer. Journal of Technology Transfer, vol.24, no 2-3, pp. 111-123.

Etzkowitz H., Webster A., Gebhardt C., Cantisano Terra B.R. (2000) The Future of the University and the University of the Future: Evolution of Ivory Tower to Entrepreneurial Paradigm. Research Policy, vol. 29, pp. 313-330.

Feller I. (1990) Universities as engines of R\&D-based growth: They think they can. Research Policy, vol. 19, pp. 335-348.

Finkbeiner M., Wiedmann M., Saur K. (1998) A comprehensive approach towards product and organisation related environmental management tools. The International Journal of Life Cycle Assessment, vol. 3, no 3, pp. 169-178.

Gelderman R., van Weele A. (2005) Purchasing Portfolio Models: A critique and update. Journal of Supply Chain Management, vol. 41, no 3, pp. 19-28.

Hameri A.P., Hintsa J. (2009) Assessing the drivers of change for cross-border supply chains. International Journal of Physical Distribution \& Logistics Management, vol. 39, no 9, pp. 741-761.

Harris I., Naim M., Palmer A., Potter A., Mumford C. (2011) Assessing the Impact of Cost Optimization Based on Infrastructure Modelling on $\mathrm{CO}_{2}$ Emissions. International Journal of Production Economics, vol. 131, no 1, pp. 313-321.

Hervani A., Helms M., Sarkis J. (2005) Performance measurement for green supply chain management. Benchmarking: An International Journal, vol. 12, no 4, pp. 330-353.

Hillary R. (2004) Environmental management systems and the smaller enterprise. Journal of Cleaner Production, vol. 12, pp. 561-569.

Hoctor K., Keating I. (2009) Back to Business Local Solutions, London: British Chambers of Commerce, Local Government Association.

Hong-MinhS.M., DisneyS.M., Naim M.M. (2000) The dynamics of emergency transhipment supply chains. International Journal of Physical Distribution \& Logistics Management, vol. 30, no 9, pp. 788-816.

Honkasalo A. (1998) The EMAS Scheme: A management tool and instrument of environmental policy. Journal of Cleaner Production, vol. 6, pp. 119-128.

IEMA (2009) IEMA Acorn Scheme. Available at: http://www.iema.net/ems/acorn_scheme, accessed 07.07.2009.

IEMA (2011) The EMAS Regulation. Available at: http://www.iema.net/ems/emas/regulation, accessed 15.09.2011.

Inzelt A. (2004) The evolution of university - industry - government relationships during transition. Research Policy, vol. 33, pp. 975-995.

Jain V., Benyoucef L. (2008) Managing long supply chain networks: Some emerging issues and challenges. Journal of Manufacturing Technology Management, vol. 19, no 4, pp. 469-496.

Klaver J., Jonker J. (1998) The significance of recent EMS standards as an impetus for improvement. Eco-Management \& Auditing, vol. 5, no 1, pp. 1-5.

KPMG (2010) The Public Sector Austerity Agenda \- What will it mean for suppliers?Available at: http://www.kpmg. co.uk/email/Restructuring/165160/Story02.html, accessed 03.07.2012.

Lee A. (1997) Working together? Academic literacies, co-production and professional partnerships, Literacy and Numeracy Studies, vol. 7, no 2, pp. 65-82.

Linna P., Pekkola S., Ukko J., Melkas H. (2010) Defining and measuring productivity in the public sector: Managerial perceptions. International Journal of Public Sector Management, vol. 23, no 3, pp. 300-320.

Manuj I., Mentzer J.T. (2008) Global supply chain risk management strategies. International Journal of Physical Distribution \& Logistics Management, vol. 38, no 3, pp. 192-223.

Markley M.J., Davis L. (2007) Exploring future competitive advantage through sustainable supply chains. International Journal of Physical Distribution \& Logistics Management, vol. 37, no 9, pp. 763-774.

Martin M. (ed.) (2000) The Management of University-Industry Relations: Five Institutional Case Studies from Africa, Europe, Latin America and the Pacific Region, Paris: UNESCO.

Matthews D. (2005) Strategic procurement in the public sector: A mask for financial and administrative policy. Journal of Public Procurement, vol. 5, no 3, pp. 388-389.

McCue C.P., Gianakis G.A. (2001) Public Purchasing: Who's minding the store? Journal of Public Procurement, vol. 1, no 1, pp. 71-95.

McIvor R., Humphreys P., McAleer E. (1997) The Evolution of the purchasing function. Journal of Strategic Change, vol. 6, pp. 165-179.

Murray G. (2001) Improving purchasing contribution - The purchasing strategy of buying council. International Journal of Public Sector Management, vol. 14, no 5, pp. 391-410.

Nieminen M., Kaukonen E. (2001) Universities and R\&D Networking in a Knowledge-Based Economy, Helsinki: Sitra.

Palomares-Soler M., Thimme P.M. (1996) EMAS and ISO 14001 compared. European Environmental Law Review, vol. 5, no 8-9, pp. 247-251.

Pane Haden S.S., Oyler J.D., Humphreys J.H. (2009) Historical, practical and theoretical perspectives on green management. Management Decision, vol. 47, no 7, pp. 1041-1055.

Paulraj A., Chen I., Flynn J. (2006) Levels of Strategic Purchasing: Impact on supply integration and performance. Journal of Purchasing and Supply Chain Management, vol. 12, pp. 107-122.

Piercy N.F, Cravens D.W., Lane N. (2010) Thinking strategically about pricing decisions. Journal of Business Strategy, vol. 31, no 5, pp. 38-48.

Plant E., Yusen X., White G.R.T. (2015) Green Supply Chain Management in Chinese Electronic Manufacturing Organisations: An analysis of senior managements' perceptions. International Journal of Social Ecology and Sustainable Development, vol. 6, no 3, pp. 21-30.

Quayle M. (1998) The impact of strategic procurement in the UK Government sector. International Journal of Public Sector Management, vol. 11, no 5, pp. 397-413.

Quayle M., Quayle S. (2000) The Impact of Strategic Procurement in the UK further and higher education sectors. The International Journal of Public Sector Management, vol. 13, no 3, pp. 260-284. 
Ranga M., Etzkowitz H. (2010) Creative reconstruction - Towards a triple helix innovation strategy in Central and Eastern Europe Countries. Theory and Practice of Triple Helix Model in Developing Countries: Issues and Challenges (eds.M. Saad, G. Zawdie), London: Routledge, pp. 249-282.

Razak A.A., Saad M. (2007)The role of universities in the evolution of the Triple Helix culture of innovation network: The case of Malaysia. International Journal of Technology Management and Sustainable Development,vol.6, no 3, pp. 211-225.

Razak A.A., White G.R.T. (2015) The Triple Helix Model for Innovation: A holistic exploration of barriers and enablers. International Journal of Business Performance and Supply Chain Modelling, vol. 7, no 3, pp. 278-291.

Reck R., Long B. (1998) Purchasing: A Competitive Weapon. Journal of Purchasing and Material Management, vol. 24, no 3, pp. 2-8.

Rink D., Fox H. (1999) Strategic procurement planning across the products sales cycle: A conceptualisation. Journal of Marketing Theory and Practice, vol. 7, no 2,pp. 28-42.

Roberts M. (1995a) Akzo Nobel, Ciba first for EMAS. Chemical Week, vol. 157, no 9, p. 41.

Roberts M. (1995b) Transatlantic sparks over EMAS, ISO 14001.Chemical Week, vol. 157, no 5, p. 14.

Roberts M. (1996) National guidelines cover part of EMAS. Chemical Week, vol. 158, no 7, p. 15.

Ruzicka P. (2004) The EMAS scheme in the Czech Republic. Czech Industry, no 11, p. 1.

Schapper P., Matla J.N., Gilbert D. (2006) An analytical framework for the management and reform of public procurement. Journal of Public Procurement, vol. 6, no 1, pp. 1-26.

Schartinger D., Schibany A., Gassler H. (2001) Interactive relations between universities and firms: Empirical evidence for Austria. The Journal of Technology Transfer, vol.26, no 3, pp. 255-268.

Shi. Y., Gregory. M., Naylor. M. (1997) International manufacturing configuration map: A self assessment tool of international manufacturing capabilities. Integrated Manufacturing Systems, vol. 8, pp. 273-282.

Staples W., Dalrymple J. (2011) Exploring Infrastructure Procurement by Australian State Governments. International Journal of Managing Projects in Business, vol. 4, no 3, pp. 512-523.

Strachan P., Haque M., McCulloch A. (1997) The Eco-Management and Audit Scheme: Recent experiences of UK participating organizations. European Environment, no 7, pp. 25-33.

UN (1987) Report of the World Commission on Environment and Development: Our Common Future, Vienna: United Nations. Available at: http://www.un-documents.net/wced-ocf.htm, accessed 02.02.2014.

URS (2010) The City's Role in Providing for the Public Equity Financing Needs of UK SMEs, London: URS Corporation.

Vickery S., Jayaram J., Droge C., Calantone R. (2003) The effects of an integrative supply chain strategy on customer service and financial performance: An analysis of discrete verse indirect relationships. Journal of Operations Management, vol. 21, no 5, pp. 523-539.

White G.R.T., James P. (2014) Extension of Process Mapping for the Identification of 'Green Waste'. Benchmarking: An International Journal, vol. 21, no 5, pp. 835-850.

White G.R.T., Lomax M. (2010) Environmental Management Systems: Costs, benefits and an activity theory approach to understanding their knowledge-generating capabilities. The Environmentalist, no 100, pp. 12-16.

White G.R.T., Lomax M., Parry G. (2014a) The Implementation of an Environmental Management System in the Not for Profit Sector. Benchmarking: An International Journal, vol. 21, no 4, pp. 509-526.

White G.R.T., Samson P., Rowland-Jones R., Thomas A.J. (2009) The implementation of a quality management system in the not-for-profit sector. The TQM Journal, vol. 21, no 3, pp. 273-283.

White G.R.T., Sarpong D., Ndrecaj V. (2015) Sustainable packaging: Regulations and operational challenges in a manufacturing SME. International Journal of Social Ecology and Sustainable Development, vol. 6, no 3, pp. 31-40.

White G.R.T., Wang X., Li D. (2014b) Inter-Organisational Green Packaging Design: A case study of influencing factors and constraints in the automotive supply chain. International Journal of Production Research, vol. 53, no 21, pp. 6551-6566.

Wilding R. (2012) The Logistics of the Games. Management Focus, no 32, pp. 22-23.

Wolff M.F. (2006) Global innovation models changing. Research Technology Management, vol. 49, no 4, pp. 5-6.

Zheng J., Knight L., Harland C., Humby S., James K. (2007) An analysis of research into the future of purchasing and supply management. Journal of Purchasing \& Supply Management, vol. 13, no 1, pp. 69-83. 